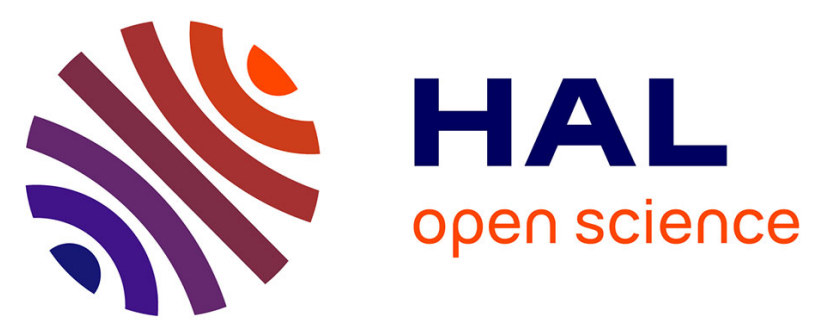

\title{
Impact of copper nanoparticles on porcine neutrophils: Proposition of an ultrasensitive characterization factor using chemiluminescence information and USEtox assessment model
}

\author{
Yubing Pu, Bertrand Laratte, Robert Marks, Rodica Elena Ionescu
}

\section{To cite this version:}

Yubing Pu, Bertrand Laratte, Robert Marks, Rodica Elena Ionescu. Impact of copper nanoparticles on porcine neutrophils: Proposition of an ultrasensitive characterization factor using chemiluminescence information and USEtox assessment model. Materials Today Communications, 2017, 11, pp.68-75. 10.1016/j.mtcomm.2017.02.008 . hal-01489194

\author{
HAL Id: hal-01489194 \\ https://hal.science/hal-01489194
}

Submitted on 14 Mar 2017

HAL is a multi-disciplinary open access archive for the deposit and dissemination of scientific research documents, whether they are published or not. The documents may come from teaching and research institutions in France or abroad, or from public or private research centers.
L'archive ouverte pluridisciplinaire HAL, est destinée au dépôt et à la diffusion de documents scientifiques de niveau recherche, publiés ou non, émanant des établissements d'enseignement et de recherche français ou étrangers, des laboratoires publics ou privés. 


\title{
Impact of copper nanoparticles on porcine neutrophils: ultrasensitive characterization factor combining chemiluminescence information and USEtox assessment model
}

\author{
Yubing Pu ${ }^{\mathrm{a}, \mathrm{b}}$, Bertrand Laratte ${ }^{\mathrm{b}, \mathrm{c}}$, Robert S. Marks ${ }^{\mathrm{d}}$, Rodica E. Ionescu ${ }^{\mathrm{a}, *}$ \\ a Laboratoire de Nanotechnologie et d'Instrumentation Optique, Institut Charles Delaunay, Université de Champagne, Université de Technologie de Troyes, \\ UMR CNRS 6281, 12 Rue Marie Curie CS 42060, 10004 Troyes Cedex, France \\ ${ }^{\mathrm{b}}$ Centre de Recherches et d'Etudes Interdisciplinaires sur le Développement Durable, Institut Charles Delaunay, Université de Technologie de Troyes, UMR \\ CNRS 6281, 12 Rue Marie Curie CS 42060, 10004 Troyes Cedex, France \\ ${ }^{\mathrm{c}}$ Institute of Mechanics and Engineering, Arts et Métiers ParisTech, UMR-CNRS 5295, Esplanade des Arts et Métiers, 33405 Talence Cedex, France \\ ${ }^{\mathrm{d}}$ The Avram and Stella Goldstein-Goren Department of Biotechnology Engineering, Ben-Gurion University of the Negev, PO Box 653,84105 Beer-Sheva, \\ Israel
}

Keywords:

Copper nanoparticles

Porcine neutrophils

in vitro chemiluminescence

USEtox model

Characterization factor

\begin{abstract}
A B S T R A C T
There is a need by the European Commission (EC) regulations, as well as others, to reduce the use of in vivo toxicity tests made on animals. Conventional in vitro tests were designed for non-nanoparticle sized entities, and therefore do not necessarily assess the adverse impacts of engineered nanoparticles (ENPs) on humans. Life cycle assessment (LCA) is a widely used methodology for evaluating the environmental performance of products. Nevertheless, the application of LCA on ENPs is difficult because the characterization factors (CFs) of ENPs, as significant input parameters in LCA, remain a major unknown. It is a premise of this study to monitor the chemiluminescence $(\mathrm{CL})$ spectra resulting from the reactive oxygen species (ROS) trigger made from the presence of copper nanoparticles (CuNPs) to porcine neutrophils in vitro, thereby enabling to calculate the porcine and human toxicity CFs. The framework of a scientific consensus model, USEtox model, is selected and the midpoint of $C F$ is set as the inflammation of pig or human. Finally, the present study recommends human and porcine inflammation CFs of CuNPs in Europe to be 1.07 and 2.90 CTU (comparative toxic units) respectively.
\end{abstract}

\section{Introduction}

With the rapid development of newly engineered nanoparticles (ENPs) [1-3], and their putative introduction to the environment, there are serious safety concerns towards consumers and production staff and therefore should be considered since the ENPs are likely to enter the bloodstream of mammals via skin, inhalation and ingestion [4-6]. Neutrophils are an abundant type of white blood cell in mammals and are considered to be one of the earliest and most prominent immune defense responders, acting through various mechanisms including phagocytosis, degranulation, etc [7]. Once ENPs invade a blood system, neutrophils will find a role to play as an essential part of the innate immune system [8]. Many experiments have been performed to investigate the mechanisms of interactions between ENPs and human neutrophils [5,9-11]. However, to the best of our knowledge, using neutrophils to assess the toxicity of ENPs has never been reported and is the premise of our present study. In addition, when evaluating the potential impact of ENPs-containing products (especially the under-design ones) to humans, the experimentations fall short of expectation being either insufficient or impractical. Therefore, many assessment methods for human toxicity have been developed to help relieve the pressure of animal experimentation and provide the end-user with a decision-making tool [12-14]. One such method is the life cycle assessment (LCA) method that thrives to be an internationally standardized tool and has been recommended by the European Commission (EC) $[15,16]$. Characterization factors (CFs) are essential parameters for LCA and reflect the potential environmental impacts and relative importance of materials [17]. Nevertheless, there is a complete lack of human toxicity CFs towards various ENPs [18].

The authors have selected copper nanoparticles (CuNPs) as the representative ENPs, to in vitro investigate the chemiluminescence of freshly isolated neutrophils from pigs. The pig is usually considered as an excellent animal biomedical model for human, because of the many similarities between human and pig [19,20]. The present 

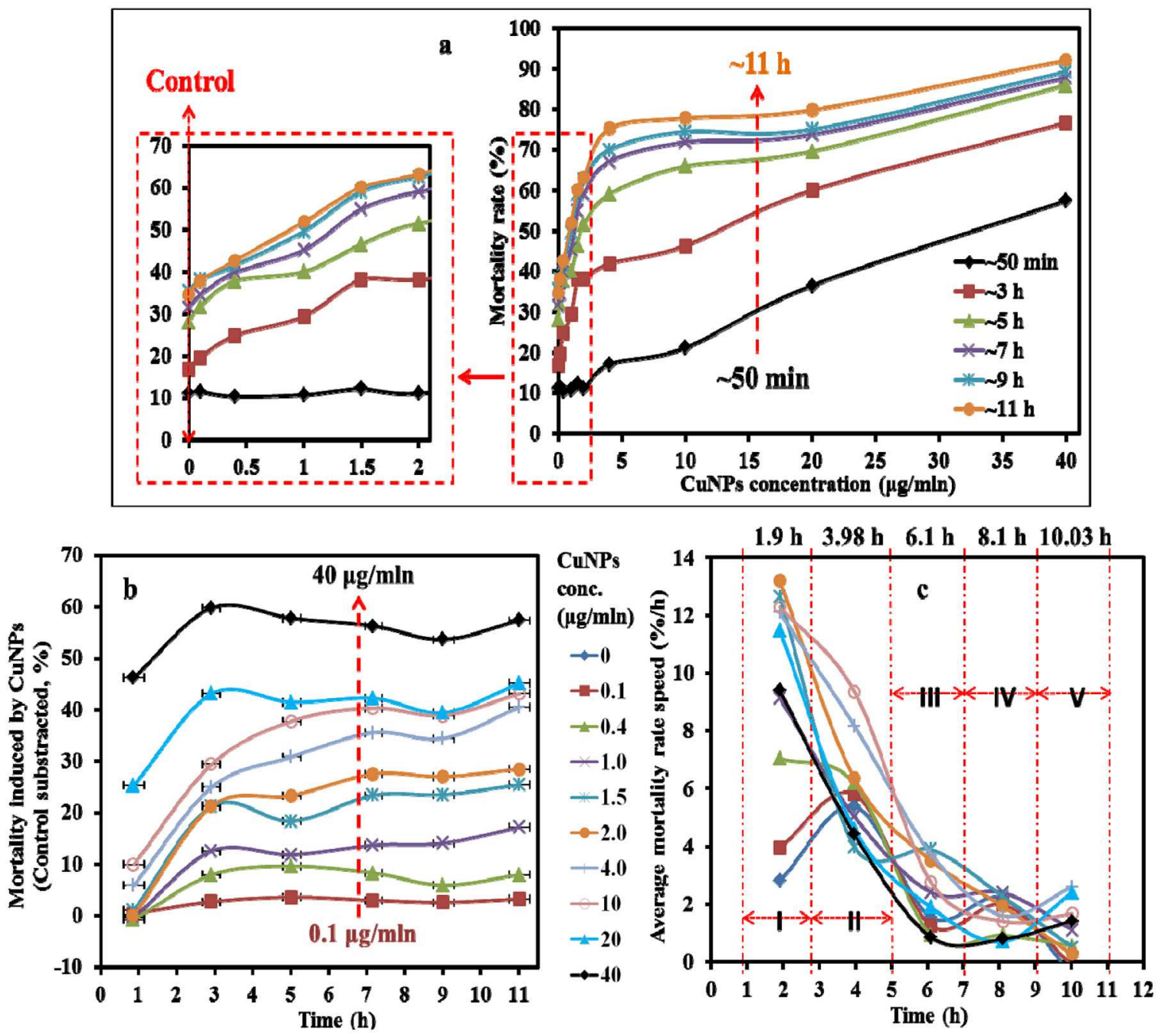

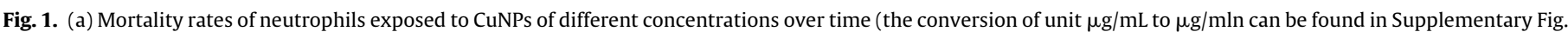

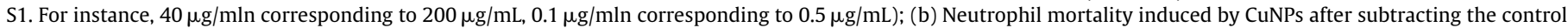

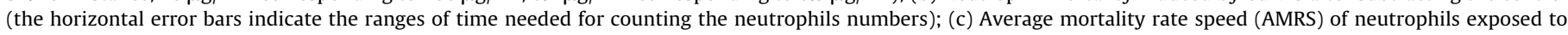

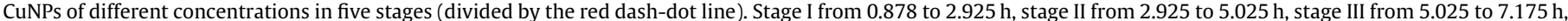

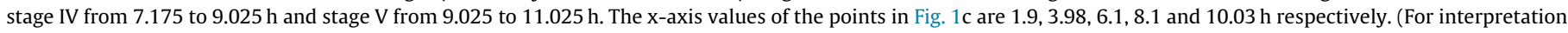
of the references to colour in this figure legend, the reader is referred to the web version of this article.)

work has two purposes. The first aim concerns the investigation of the impact of CuNPs on life-status of porcine neutrophils while observing their impact via chemiluminescent $(\mathrm{CL})$ kinetic imprinting and scanning electron microscopy (SEM) characterization. The second aim uses the CL results to estimate porcine and human inflammation CFs of CuNPs under the framework of a scientific consensus model.

\section{Materials and methods}

\subsection{Materials and instrumentation}

Heparin sodium (H3393), histopaque (10771), dextran (D4876), trypan (T8154), dimethyl sulfoxide (DMSO, D4540), glutaraldehyde (G7651), copper NPs (CuNPs, <100 nm, 634220) were purchased from Sigma-Aldrich. Ethanol (02860) was provided by Fluka (Lyon, France). Luminol/Enhancer (Bio-Rad HRP, CA) was used to amplify chemiluminescence activity. Phosphate buffered saline (PBS buffer, $\mathrm{pH}$ 7.4) was freshly prepared in our lab using sodium chloride (S7653), sodium phosphate dibasic (94046) and sodium phosphate monobasic (71505) purchased from Sigma (France). Zymosan A
(Z4250, sigma) suspension, used as a stimulating agent, in previous prepared Krebs-Ringer phosphate (KRP) medium was opsonized for $30 \mathrm{~min}$ at $38^{\circ} \mathrm{C}$ in a water bath (Grant Instruments Type VF, Cambridge Ltd, UK) before being used.

Prior to preparing "a" stock analyte solution, an autoclave-steam sterilizer (2540 ML-Tuttnauer, Netherlands) was used to sterilize deionized water produced by Millipore water purification system (Molsheim, France). A conventional optical microscope was used to count cells by a hemocytometer (Hausser scientific, Horsham, USA). Different dilutions of nano copper solutions were well dispersed by an ultrasonic water bath (Elmasonic $\mathrm{S} 3 \mathrm{OH}$ ) and a vortex mixer (G560E, Scientific Industries Inc., USA). A centrifuge (Universal 320R, Andreas Hettich GmbH, Germany) was employed. The morphology of cells was characterized by a field emission scanning electron microscopy (Hitachi SU8030, Japan) with an accelerating voltage of $10 \mathrm{kV}$.

\subsection{Experimentation methodologies}

The experiments in this study were first based on a representative group of four pigs, and once similar tendencies were observed, 

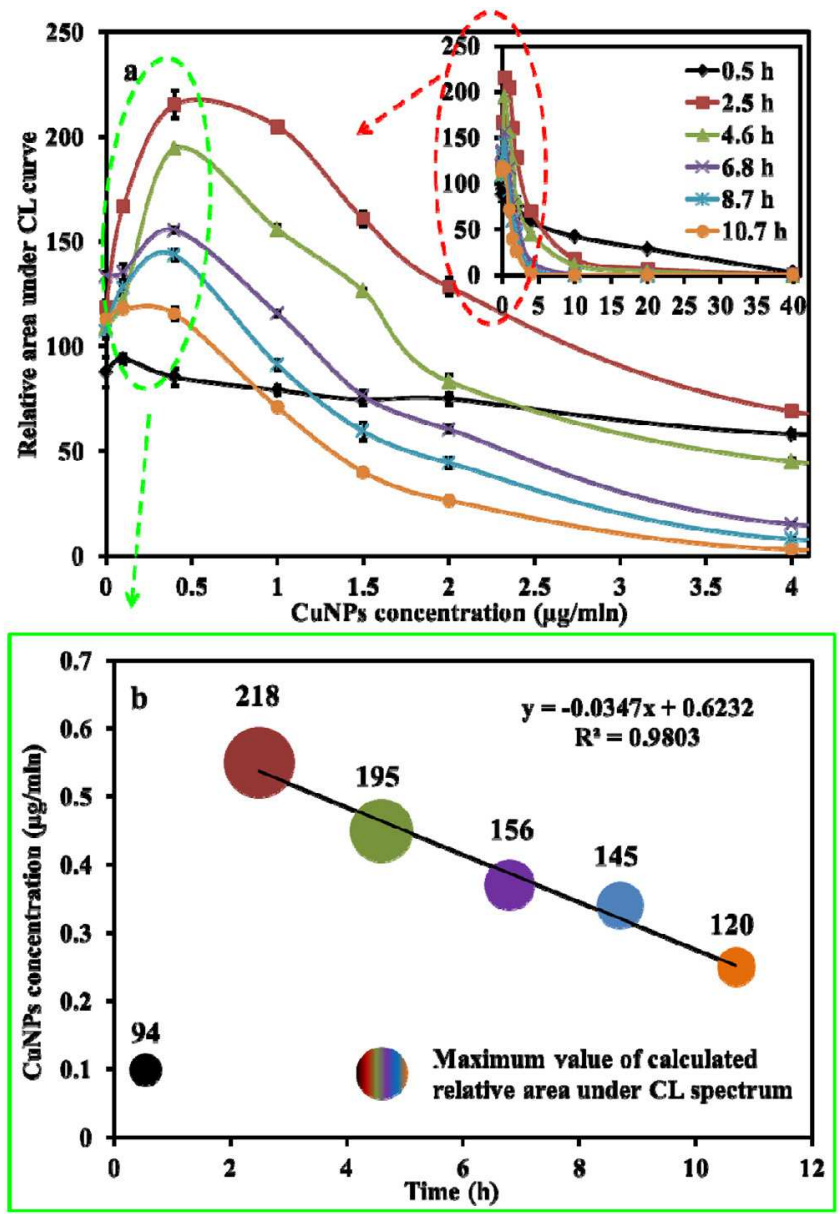

Fig. 2. (a) Calculated relative areas under CL spectra of neutrophils exposed to different concentrations of CuNPs for different durations; Error bars represent the standard deviation based on three replicas in one experiments. (b) Maximum values of calculated relative area under CL spectrums extracted from Fig. 2a. The size of the circle represents the relative area value.

it was sufficient to rely on experimental results from a single pig with replicas made thrice. It should be noted, however, that the calculation of characterization factors used the results from all four pigs.

\subsubsection{Neutrophilisolation}

For each experiment, porcine blood was collected from the external jugular vein of a clinically healthy domestic pig ( $\leq 6$ month, $100-110 \mathrm{~kg}$ ) in the morning between $4: 30$ to $5: 10$ in an slaughter housenear Troyes (Sicaba, Pont-Sainte-Marie, France). The use of pigs in this study was approved by the Service of Animal Health Protection and Environment in the Prefecture of Aube (approval no. 10-387-901). In the day of the experiment, $50 \mathrm{~mL}$ porcine blood was collected and anticoagulated with $7 \mathrm{mg}$ Heparin sodium dissolved in $1 \mathrm{~mL} \mathrm{KRP} \mathrm{medium.} \mathrm{According} \mathrm{to} \mathrm{the} \mathrm{gradient} \mathrm{density} \mathrm{centrifuga-}$ tion method as previously described $[11,21,22]$, a slightly modified isolation protocol of porcine neutrophils was used and described in detail in the Supplementary material (Section S1).

\subsubsection{Mortality rates calculation and chemiluminescence} measurement

The freshly isolated porcine neutrophils were exposed to CuNPsat ten different concentrations in ten eppendorf tubes $(1 \mathrm{~mL})$ at $20^{\circ} \mathrm{C}$ for about $11 \mathrm{~h}$. Here, a specific concentration unit was introduced to better understand the relationship between CuNPs and neutrophils: $\mu \mathrm{g} / \mathrm{mln}$, which means the mass of CuNPs per million neutrophils (The conversion method and an example were shown in Supplementary Fig. S1). By subjecting the tube for a few seconds of hand-shaking we assume that both neutrophils and CuNPs were well dispersed. The 10 concentrations of CuNPs were $0,0.1$, $0.4,1,1.5,2,4,10,20,40 \mu \mathrm{g} / \mathrm{mln}$, respectively. During exposure, the mortality rates of neutrophils were calculated at six selected time points $(0.875,2.925,5.025,7.175,9.025$ and $11.025 \mathrm{~h})$ with Trypan blue and Hemacytometer (Supplementary Fig. S2 illustrating the cell counting procedures). In addition, during the exposure, chemiluminescence $(\mathrm{CL})$ spectra were also recorded for each concentration over six selected periods of time $(0.5,2.5,4.6,6.8,8.7$ and $10.7 \mathrm{~h}$, respectively). CL measurements were performed within standard 96 wells Costar microtiter-plates (Corning, USA) and a luminometer (Luminoskan Ascent, Thermo Fisher Scientific, USA). The relative areas under each $C L$ spectrum were respectively calculated (an example of an original control CL spectrum is shown in Supplementary Fig. S3).

\subsubsection{Morphology characterization of CuNPs and neutrophils}

Three different sample preparation procedures were applied for the surface morphology characterization of CuNPs. For apristine sample, CuNPs powder without any treatment was spread onto a carbon conductive tape; for CuNPs in water, $200 \mu \mathrm{g} / \mathrm{mL}$ CuNPs solution with $\mathrm{ddH}_{2} \mathrm{O}$ was ultrasonicated for $5 \mathrm{~min}$, followed by deposition of one drop of solution onto the gold-palladium covered glass substrate then dried for SEM imaging; furthermore, for CuNPs in KRP buffer solution, $200 \mu \mathrm{g} / \mathrm{mL}$ CuNPs in KRP solution was ultrasonicated for $5 \mathrm{~min}$ then followed the same procedures as for neutrophils to prepare the SEM samples. The preparation of goldpalladium covered glass substrate was described in Supplementary material (Section S5).

The neutrophils exposed to selected concentrations of CuNPs were all fixed in $2.5 \mathrm{wt} \%$ glutaraldehyde aqueous solutions overnight after certain time intervals. Then, the neutrophil suspension was centrifuged ( $4000 \mathrm{rpm}, 5 \mathrm{~min}$ ), followed by a stepwise dehydration using a series of graded ethanol aqueous solutions of $30 \%, 50 \%, 70 \%, 100 \%$ and $100 \%$ respectively. Each step was conducted for $10 \mathrm{~min}$ at room temperature followed by centrifugation (4000 rpm, $5 \mathrm{~min}$ ). Hereafter, the neutrophils were well dispersed in absolute ethanol, and deposited as $2.5-5 \mu \mathrm{L}$ solution onto the surface of prepared glass substrates. Prior to SEM characterization, the samples were dried freely in the hood and covered with a thin layer (2-3 nm) of gold-palladium to suppress the charging effects.

\subsection{Characterization factor}

Life cycle impact assessment (LCIA) is one of the conventional steps when conducting life cycle assessment (LCA), which could translate the emissions into indicators that reflect the environment and its health impacts [23]. The typical calculation in LCIA is based on the following equation:

Ecosystemorhumanimpact $=\sum M \times C F$

where $C F$ is the substance-specific characterization factor that expresses the potential impact of each single elementary material flow $(M)$ contributing to the total impacts [24]. Characterization factor $(C F)$ thus facilitates the comparisons between the different substances in terms of their ability of contribution to the impacts on ecosystem or human.

\subsubsection{Selection of characterization model}

Many characterization methods are available to calculate the CFs for the human toxicity impact category, such as IMPACT 2002+ [25], ReCiPe [26], EDIP2003 [27], MEEuP [28], USEtox [29], etc. A comprehensive comparison between these models were performed by 

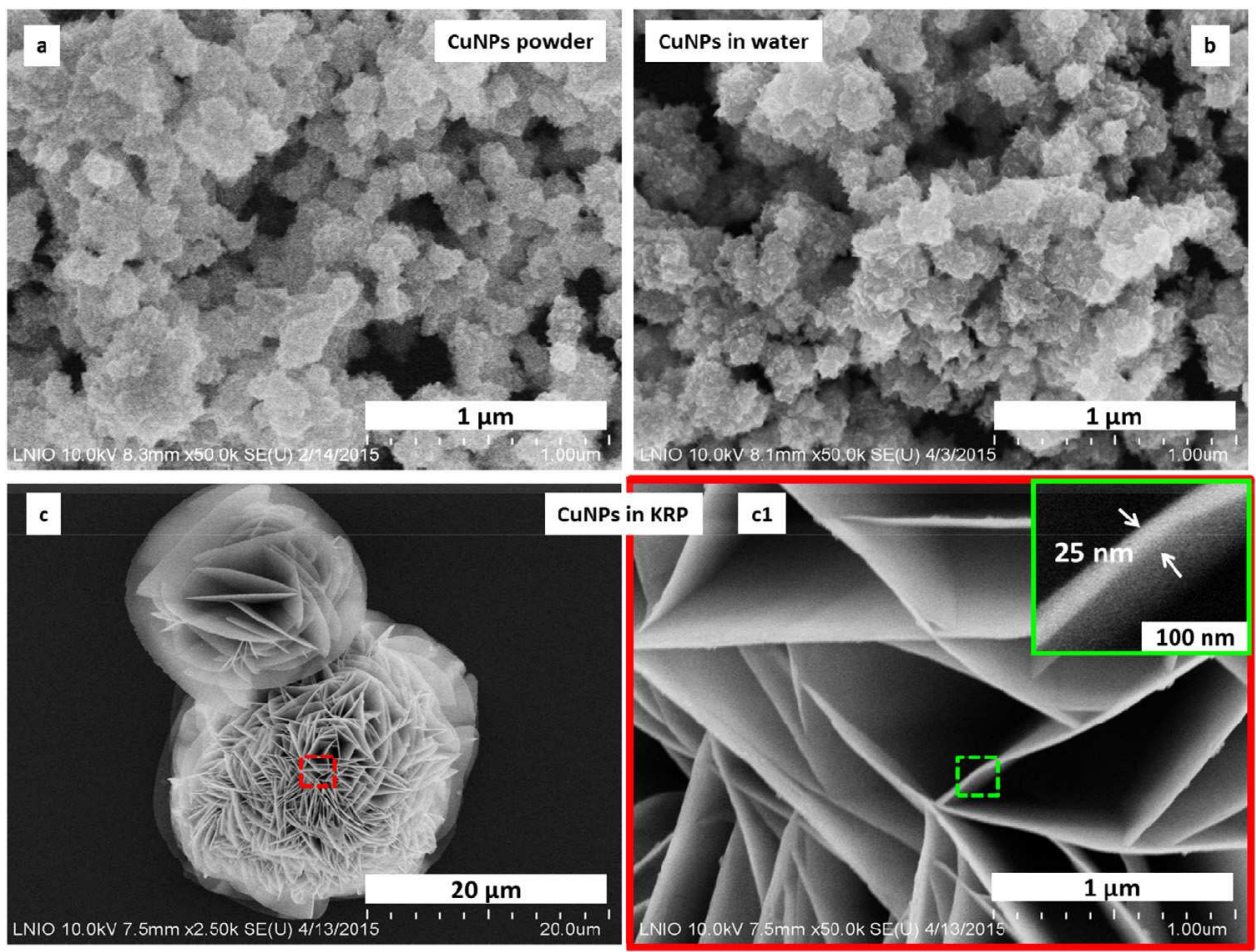

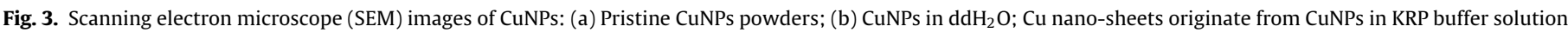
with (c) 2500 magnification times and (c1) 50000 magnification times. The inset in c1 is a SEM image showing that the thickness of the nano-sheet is around 25 nm.

Joint Research Centre of European Commission [16]. The compared models were rated under the criteria defined in ILCD Handbook: LCIA - Framework and Requirements [30]. Several features make the USEtox model stand out compared to others [16]. For example, the USEtox model accounts for a chemical's fate in the ecosystem, human exposure and differences in toxicological response, while the MEEup model is not [16]. In addition, the USEtox model includes all vital model elements in a scientifically sound way for most substances, which makes it have the best compliance with the science-based criteria [16]. Therefore, the USEtox has been recommended as a scientific consensus method for the calculation of CFs by many international organizations such as the European Commission (EC), Business Council for Sustainable Development (WBCSD), etc $[16,31,32]$. In this study, the framework of the USEtox model has been selected for calculating the porcine and human toxicity CFs.

\subsubsection{Model concept}

In USEtox, a characterization factor $(C F)$ describes a potential impact on human health related to the emission of a given substance. It can be expressed by [29]:

$\mathrm{CF}=\mathrm{FF} \times \mathrm{XF} \times \mathrm{EF}$

The human toxicity $C F$ has a unit of comparative toxic units (CTU), which represents the estimated increase in morbidity in the total human population, per unit mass of a substance emitted (cases $/ \mathrm{kg}_{\text {emission }}$ ). The fate factor, $F F$ (unit: day), represents the residence time of a substance in a particular environment (such as freshwater). The exposure factor, $X F$ (unit: day $^{-1}$ ), reflects the rate at which a pollutant is able to transfer from a receiving compartment into the human population through a series of exposure pathways. The $E F$ is the human effect factor (unit: cases $/ \mathrm{kg}_{\text {intake }}$ ) and reflects the change in the life time disease probability, due to the change in life time intake of a pollutant.
It should be highlighted that the chemiluminescence of exposed porcine neutrophils provides the essential data for calculating the effect factors (EFs) of CuNPs for both pigs and humans. The humanequivalent toxicological data could be obtained by applying an extrapolation factor for interspecies (pig to human) differences, which makes it possible to use toxicological data on laboratory animals to calculate the human toxicity CFs.

\subsubsection{Fate factor and exposure factor calculation}

The fate factor $(F F)$ depends on the properties of the substances and the interaction compartments (e.g. from urban air to fresh water). Compared to materials in bulk phases, the ENPs show different fate behaviors after entering the environment. Several previously published studies proposed nano-specific fate models based on the colloidal science and the parameters of ENPs [15,33-36]. Main differences between these models are the different compartments (air, water and soil) and removal processes considered. A recently published model by our group took water and sediment account and proposed a FF of 1.803 day of CuNPs in Europe freshwater for eco-toxicity assessment [37]. In terms of the USEtox model, the FFs of a substance in a given compartment are the same for ecotoxicity and human toxicity [32]. Thus, in this study, the FF of 1.803 day of CuNPs in European freshwater was applied to calculate the characterization factors of CuNPs. The further details about the fate model could be found in the related reference [37].

In this study, the exposure factor $(X F)$ was set as 1 conservatively due to the lack of bioaccumulation factors (BAF) of ENPs. The experimental data are unavailable for BAF and the estimation of BAF is also impracticable due to the invalid partition coefficients for ENPs [38]. Nevertheless, as one important factor in $C F$ calculation, $X F$ may have a big influence on the final $C F$ values. Therefore, further investigations of $X F$ are necessary in the future. 

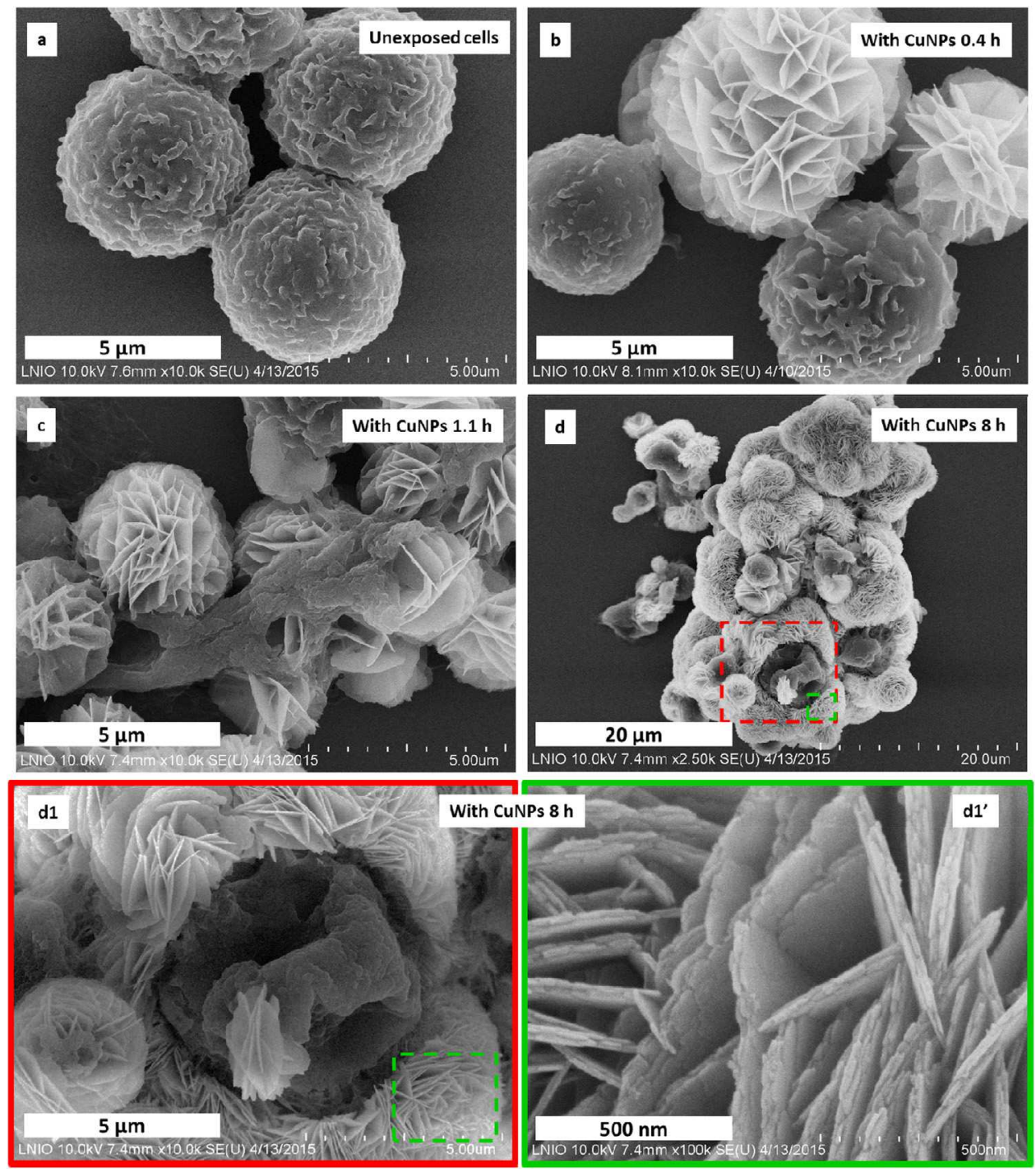

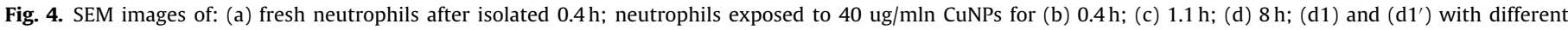
magnification times are SEM images zoomed in from (d).

\subsubsection{Effect factor calculation}

The $E F$ (cases $/ \mathrm{kg}_{\text {intake }}$ ) in this paper reflects the change of the inflammation's probability due to the change of the CuNPs intake in the whole life time of either pig or human. Under the assumption of linearity in dose-response (up to where the life time disease probability is 0.5), EF equals [29]:

$\mathrm{EF}=\frac{0.5}{\mathrm{ED} 50}$

ED50 ( $\mathrm{kg}_{\text {lifetime }}{ }^{-1}$ ) is the dose amount of ingested substance for either animal $\left(E D 50_{\mathrm{a}}\right.$, e.g. pig) or human $\left(E D 50_{\mathrm{h}}\right)$ during whole its life time that causes an inflammation with a probability of $50 \%$. The $E D 50_{\mathrm{h}}$ of a human is calculated based on the following equation [29]:

$\mathrm{ED} 50_{\mathrm{h}}=\frac{E D 50_{\mathrm{a}, t} \cdot B W_{\mathrm{h}} \cdot L T_{h} \cdot N}{A F_{a} \cdot A F_{\mathrm{t}} \cdot 10^{6}}$

$E D 50_{a, t}\left(\mathrm{mg} \mathrm{kg}^{-1} \mathrm{day}^{-1}\right)$ is the dose for animal during exposure time $t$ (day). $A F_{\mathrm{a}}$ is the extrapolation factor for interspecies differences (pig to human is 1.1) [29], because the $E D 50_{\mathrm{h}}$ is derived from the toxic data of pigs. $B W_{\mathrm{h}}$ and $L T_{\mathrm{h}}$ respectively represent average body weight ( $70 \mathrm{~kg}$, data from USEtox) and average lifetime of human (70 years, data from USEtox). $N$ is the number of days per year ( 365 days.year ${ }^{-1}$ ). Since chronic toxicity values have priority in USEtox, thus an extrapolation factor $A F_{\mathrm{t}}$ of 5 for acute to chronic exposure is applied.

In this study, in order to compare the impacts of CuNPs on human and pig, both porcine and human CFs were calculated. The $E D 50_{\mathrm{a}}$ of pig can be calculated by:

$\mathrm{ED}^{2} 0_{a}=\frac{E D 50_{\mathrm{a}, t} \cdot B W_{a} \cdot L T_{a} \cdot N}{A F_{\mathrm{t}} \cdot 10^{6}}$

where $B W_{\mathrm{a}}$ represents average body weight $(110 \mathrm{~kg}$, data from the abattoir). The lifetime of $\operatorname{pig}\left(L T_{\mathrm{a}}\right)$ is between $10-20$ years [20]. Thus, here, an average $L T_{\mathrm{a}}$ value of 15 years is used.

In this study, it was assumed that there are no individual differences among pigs or humans and when the amount of ROS produced by neutrophils decreases to the $50 \%$ amount of ROS of a control sample, the inflammation probability is $50 \%$. Thereby, the $E D 50_{a, t}$ values were calculated based on the $50 \%$ calculated relative area under CL spectrum of the control samples. The detailed calculation method of $E D 50_{a, t}$ is described in Supplementary Fig. S4. 


\section{Results and discussion}

\subsection{Effects of CuNPs on neutrophils: mortality rates}

Fig. 1a shows that the exposure durations and concentrations of CuNPs have both positive correlations on the mortality rates of neutrophils. For instance, after exposure for about $11 \mathrm{~h}$, the mortality rate of neutrophils with $40 \mu \mathrm{g} / \mathrm{mln}$ CuNPs was found to be $92.04 \%$, while that of no-CuNPs control neutrophils (unexposed cells to CuNPs) was merely $34.63 \%$. Fig. 1b displays the mortality induced specifically by CuNPs by subtracting the mortality rates of the noCuNPs control neutrophils. Within about $3 \mathrm{~h}$, all the nine curves showed obvious upward trends. After the initial increase, the mortality rates induced by CuNPs remain steady, which means that the CuNPs may no longer influence the mortality of neutrophils after an exposure of 3-7 h. Fig. 1c shows the average mortality rate speed (AMRS) of neutrophils exposed to CuNPs. The detailed calculations were described by equation S4 and S5 in Supplementary material. In this study, the mortality rates of neutrophils were tested at six time points $(0.875,2.925,5.025,7.175,9.025$ and $11.025 \mathrm{~h})$, which divided the whole test period into five stages (I, II, III, IV, V in Fig. 1c). When the concentration of CuNPs was below $0.1 \mu \mathrm{g} / \mathrm{mln}$, the AMRS of neutrophils is observed to increase at the onset (stage I and first half of stage II) then decreases (second half of stage II and stage III). In contrast, when the concentration of CuNPs is above $0.4 \mu \mathrm{g} / \mathrm{mln}$, the AMRS of neutrophils continues a rapid decrease until $7 \mathrm{~h}$ (stage I, II and III). Nevertheless, for all the neutrophils exposed to the studied concentrations, the AMRS becomes stable in stage IV and $\mathrm{V}$.

\subsection{Effects of CuNPs on neutrophils: chemiluminescence kinetics}

Inflammatory mediators such as nanomaterials can trigger neutrophils to produce reactive oxygen species (ROS) [39]. Since the intensity of light emitted by stimulated neutrophils is proportional to the production of reactive oxygen species (ROS) [40,41], neutrophils' capacity to generate ROS was indirectly estimated by conducting chemiluminescence $(\mathrm{CL})$ measurement. The relative area under the CL spectrum represents the ability of neutrophils to generate ROS and has been found to be useful for detection of inflammatory diseases [41]. Fig. 2a shows the relative areas under CL curves of neutrophils exposed to nine concentrations of CuNPs at six selected time. All the curves in Fig. 2a have a trend of rise initially then fall to 0 at different CuNPs concentrations (see insert in Fig. 2a). It reveals that low concentrations of CuNPs could stimulate neutrophils, while high concentration CuNPs could inhibit the oxidative burst of neutrophils.

The mortality rates of neutrophils with time $\sim 50 \mathrm{~min}$ are smaller than with $\sim 3 \mathrm{~h}$ (Fig. 1a). However, the amounts of ROS for $0.5 \mathrm{~h}$ are lower than for $2.5 \mathrm{~h}$ when the concentration of CuNPs less than $5 \mu \mathrm{g} / \mathrm{mln}$ (Fig. 2a). It means that the lower concentration of CuNPs $(<5 \mu \mathrm{g} / \mathrm{mln})$ stimulated neutrophils slower than higher ones.

Fig. $2 \mathrm{~b}$ presents the maximum values of the calculated relative area under CL spectra at six selected time points. Each circle indicates the given time point, at which concentration of CuNPs stimulate the neutrophils most. In Fig. $2 \mathrm{~b}$, the maximum relative area rises fast from 0.5 to $2.5 \mathrm{~h}$, then declines continuously. The porcine neutrophils generate the most ROS at about $2.5 \mathrm{~h}$. Such cellular behavior indicates that neutrophils would not be activated immediately when exposed to CuNPs. Furthermore, when the neutrophils are fully activated, the concentrations of CuNPs that most stimulate the neutrophils decrease along with time. We may infer that the neutrophils become increasingly sensitive along with their exposure to CuNPs.

\subsection{Scanning electron microscope (SEM) characterization of CuNPs}

The surface morphology of CuNPs is shown in Fig. 3. It reveals that the pristine CuNPs and the CuNPs dispersed in $\mathrm{ddH}_{2} \mathrm{O}$ are granulated and around $50-200 \mathrm{~nm}$ in diameter (Fig. 3a and b). After being dispersed in a salt-based KRP buffer solution, these same CuNPs were observed to form $\mathrm{Cu}$ nano-sheets (Fig. $3 \mathrm{c}$ and $\mathrm{c} 1$ ) due to some unknown mechanism. The plan dimension of highly anisotropic nanosheets can reach over $15 \mu \mathrm{m}$ (Fig. 3c) while the thickness is estimated around $25 \mathrm{~nm}$ (Fig. 3c1 inset).

\subsection{Rearrangement of copper nano-sheets initiated by porcine neutrophils}

Fig. 4 shows the morphology of neutrophils before and after being exposed to $40 \mu \mathrm{g} / \mathrm{mln}$ CuNPs for different durations via scanning electron microscope (SEM) imaging. Moreover, similar characterization on neutrophils exposed to $20 \mu \mathrm{g} / \mathrm{mln}$ CuNPs was also reported in Supplementary Fig. S4. The size of unexposed porcine neutrophils is about $3 \mu \mathrm{m}$ and the cells are rounded with membrane folds, as similar as the results in previous reporting $[42,19]$. It is obvious that CuNPs already changed to nano-sheets at $0.4 \mathrm{~h}$ incubation with neutrophils and the size of nano-sheets is around $3-5 \mu \mathrm{m}$. The morphology of neutrophils changed after exposure to $40 \mu \mathrm{g} / \mathrm{mln}$ CuNPs (Fig. $4 \mathrm{~b}-\mathrm{d}$ ). After incubation with CuNPs for $1.1 \mathrm{~h}$, the phagocytosis phenomenon of neutrophils was observed as shown in Fig. 4c. Interestingly, the neutrophils were surrounded by copper nano-sheet particles, at a considerably larger size (Fig. 4d). The thickness of a single copper nano-sheet covering the neutrophils, ranges from 20 to $50 \mathrm{~nm}$ (estimated from Fig. $4 \mathrm{~d} 1^{\prime}$ ) similar to the original nano-sheets in Fig. 3c1. Nevertheless, the plan dimension of nanosheets is about $2-5 \mu \mathrm{m}$, which is much smaller than the nanosheets without neutrophils. In addition, it should be noted that after neutrophils were exposed to $40 \mu \mathrm{g} / \mathrm{mln}$ CuNPs for $8 \mathrm{~h}$, the CL signal decreased to 0 , despite the fact that there were still about 10\% live neutrophils (see Fig. 1a). Here two reasons are proposed. On one hand, neutrophils may 'exhaust' themselves during their interactions with the copper particles, thus reducing their light signal output drastically, though they are observed to be alive; on the other hand, the layers of copper nano-sheets may scatter and quench some of the light produced by the CL reaction.

Moreover, it was found when the CuNPs concentration was lower than $2 \mu \mathrm{g} / \mathrm{mln}$, there was no coverage of copper nanosheets on neutrophils, while the coverage started to be observed from $2 \mu \mathrm{g} / \mathrm{mln}$ CuNPs onwards (Supplementary Fig. S5). Thus, even though the same pristine CuNPs (Fig. 3a) were used in all the experiments, the morphology of CuNPs during the experiment became complex, which may be influenced by the CuNPs concentrations and exposure time with neutrophils.

\subsection{Characterization factor calculation}

The EFs for pig and human over time (values are listed in Supplementary Table S1) were respectively calculated based on the average values of $E D 50_{a, t}$ which were derived from the chemiluminescence results. Fig. 5 shows the human and porcine inflammation CFs based on different exposure periods. To the best of our knowledge, this is the first time that the porcine toxicity CFs are reported. To simplify the comparison, the porcine toxicity $C F$ keeps the same unit (CTU) as human toxicity CF but has a slightly different meaning. The $C F$ for porcine toxicity impact represents the potential increase in morbidity in pigs per unit mass of a chemical emitted. Since the human inflammation CFs are based on the same porcine toxicological data, both human and porcine inflammation CFs display similar upward trends over time. No matter in which exposure period, the 


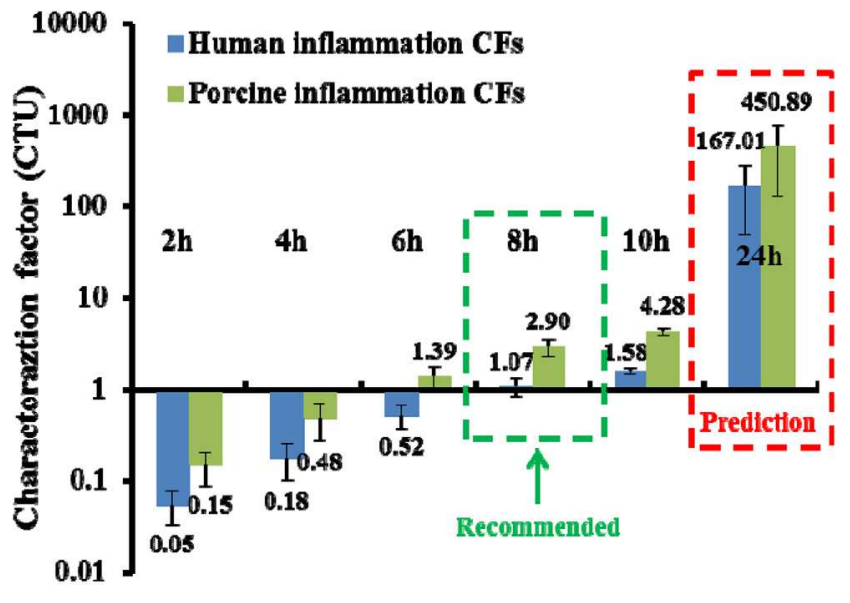

Fig. 5. Human and porcine inflammation $C F$ s for different exposure periods. Error bars represent the standard deviation based on four individual pigs. The CFs values of $24 \mathrm{~h}$ are derived from the exponential extension of the original toxic data (details can be found in Supplementary Fig. S6).

inflammation's cases of pig are 2.7 times higher than that of human. Except the employed extrapolation factor for interspecies differences (pig to human: 1.1), the different body weight and life-time between human and pig are also reasons causing the CFs variation between human and pig. The body weight of pig is about 1.6 times heavier than human, while the lifespan of pig is $\sim 4.7$ times shorter than human.

The CFs values for $24 \mathrm{~h}$ and $8 \mathrm{~h}$ are respectively about 3000 and 20 times of $C F s$ values for $2 \mathrm{~h}$. It indicates that exposure time is a significant parameter when calculating CFs. Here, we give the recommendations for using $C F s$ values of $8 \mathrm{~h}$ in the future life cycle assessment (LCA) of CuNPs containing products, because the human neutrophils are considered short-lived cells with a half-life in the circulation of approximately $8 \mathrm{~h}$ in humans [43]. Therefore, the recommended human and porcine inflammation CFs are 1.07 and 2.90 CTU respectively. Nevertheless, it should be noted that the recruitment of neutrophils is not considered, which may overestimate the CFs values.

\section{Conclusion}

In summary, a rapid and promising method to evaluate the impacts of cooper nanoparticles on pig and human via a combination of in vitro experiments and assessment model is reported. The results by further toxicity evaluation with USEtox model were considered representative, despite the fact that some assumptions and simplifications were made in the calculation of CFs. In the case of CuNPs, it was found that both the exposure time and concentrations of CuNPs have a positive correlation on neutrophil mortality rates. The CL kinetic results indicated that the neutrophils exposed $2.5 \mathrm{~h}$ to CuNPs showed the highest activity ability. In addition, an estimated rearrangement of copper nano-sheets initiated by porcine neutrophils was also presented. Furthermore, a porcine and human inflammation characterization factor of 1.07 and 2.90 CTU for CuNPs was recommended respectively. These $C F$ values for CuNPs could be used in the future for assessing the risks of CuNPs containing products by LCA method.

\section{Acknowledgments}

The authors kindly thank the Abattoir SICABA located at PontSainte-Marie for providing the fresh porcine blood. Yubing PU kindly thanks the China Scholarship Council (CSC) for his PhD scholarship in France (September 2013-March 2017).

\section{Appendix A. Supplementary data}

Supplementary data associated with this article can be found, in the online version, at http://dx.doi.org/10.1016/j.mtcomm.2017. 02.008 .

\section{References}

[1] Y.C. Cao, R. Jin, C.A. Mirkin, Science 297 (2002) 1536-1540.

[2] J.H. Park, L. Gu, G. von Maltzahn, E. Ruoslahti, S.N. Bhatia, M.J. Sailor, Nat. Mater. 8 (2009) 331-336.

[3] W. Gao, R.H. Fang, S. Thamphiwatana, B.T. Luk, J. Li, P. Angsantikul, Q. Zhang, C.-M.J. Hu, L. Zhang, Nano Lett. 15 (2015) 1403-1409.

[4] S.W. Wijnhoven, W.J. Peijnenburg, C.A. Herberts, W.I. Hagens, A.G. Oomen, E.H. Heugens, B. Roszek, J. Bisschops, I. Gosens, D. Van De Meent, Nanotoxicology 3 (2009) 109-138.

[5] K. Babin, F. Antoine, D.M. Goncalves, D. Girard, Toxicol. Lett. 221 (2013) 57-63.

[6] A.D. Maynard, Nano Today 1 (2006) 22-33.

[7] C. Nathan, Nat. Rev. Immunol. 6 (2006) 173-182.

[8] N. Borregaard, Immunity 33 (2010) 657-670.

[9] D. Couto, M. Freitas, V. Vilas-Boas, I. Dias, G. Porto, M.A. Lopez-Quintela, J. Rivas, P. Freitas, F. Carvalho, E. Fernandes, Toxicol. Lett. 225 (2014) 57-65.

[10] T.L. Hwang, C.T. Sung, I.A. Aljuffali, Y.T. Chang, J.Y. Fang, Colloids Surf. B. Biointerfaces 114 (2014) 334-341.

[11] M. Poirier, J.C. Simard, F. Antoine, D. Girard, J. Appl. Toxicol. 34 (2014) 404-412.

[12] P.J. Alvarez, V. Colvin, J. Lead, V. Stone, ACS Nano 3 (2009) 1616-1619.

[13] A. Nel, T. Xia, H. Meng, X. Wang, S. Lin, Z. Ji, H. Zhang, Acc. Chem. Res. 46 (2013) 607-621

[14] T. Gao, B.P. Jelle, L.I. Sandberg, A. Gustavsen, ACS Appl. Mater. Interfaces 5 (2013) 761-767.

[15] B. Salieri, S. Righi, A. Pasteris, S.I. Olsen, Sci. Total Environ. 505 (2015) 494-502.

[16] ILCD Handbook: Recommendations for Life Cycle Impact Assessment in the European Context, Publications Office of the European Union, Luxemburg 2011.

[17] B. Laratte, B. Guillaume, J. Kim, B. Birregah, Sci. Total Environ. 481 (2014) 588-595.

[18] R. Hischier, T. Walser, Sci. Total Environ. 425 (2012) 271-282.

[19] D. Brea, F. Meurens, A.V. Dubois, J. Gaillard, C. Chevaleyre, M.L. Jourdan, N. Winter, B. Arbeille, M. Si-Tahar, F. Gauthier, S. Attucci, Biochem. J. 447 (2012) 363-370.

[20] F. Meurens, A. Summerfield, H. Nauwynck, L. Saif, V. Gerdts, Trends Microbiol 20 (2012) 50-57

[21] R. Cramer, P. Dri, G. Zabucchi, P. Patriarca, J. Leukoc. Biol. 52 (1992) 331-336.

[22] Jack B. Cowland, N. Borregaard, J. Immunol. Methods 232 (1999) 191-200.

[23] ISO 14044: Environmental Management, Life Cycle Assessment, Requirements and Guidelines, International Standard Organization, Geneva, 2006.

[24] M.Z. Hauschild, M. Goedkoop, J. Guinée, R. Heijungs, M. Huijbregts, O. Jolliet, M. Margni, A. De Schryver, S. Humbert, A. Laurent, S. Sala, R. Pant, Int. J. Life Cycle Assess. 18 (2012) 683-697.

[25] D.W. Pennington, M. Margni, C. Ammann, O. Jolliet, Environ. Sci. Technol. 39 (2005) 1119-1128.

[26] Mark Goedkoop, Reinout Heijungs, Mark Huijbregts, An, De Schryver, Jaap Struijs, Zelm Rosalie, van Recipe (2008) A life cycle impact assessment method which comprises harmonised category indicators at the midpoint and the endpoint level. First edition Report 1: Characterisation. 2009. www.leidenuniv.nl/cml/ssp/publications/recipe_characterisation.pdf.

[27] J. Potting, M.Z. Hauschild, Background for Spatial Differentiation in Life Cycle Impact Assessment: The EDIP2003 Methodology, Danish Environmental Protection Agency, Copenhagen, 2005.

[28] R. Kemna, M. van Elburg, W. Li, R. Van Holstein, MEEUP Methodology Report, European Commission, Brussels, 2005

[29] R.K. Rosenbaum, T.M. Bachmann, L.S. Gold, M.A.J. Huijbregts, O. Jolliet, R. Juraske, A. Koehler, H.F. Larsen, M. MacLeod, M. Margni, T.E. McKone, J. Payet, M. Schuhmacher, D. Meent, M.Z. Hauschild, Int. J. Life Cycle Assess. 13 (2008) 532-546.

[30] ILCD Handbook: Framework and Requirements for Life Cycle Impact Assessment Models and Indicatiors, Publications Office of the European Union, Luxemburg, 2010.

[31] R. Hischier, B. Nowack, F. Gottschalk, I. Hincapie, M. Steinfeldt, C. Som, J Nanopart. Res. 17 (2015) 1-13.

[32] P.E. Fantke, X. Bengoa, Y., Dong, C. Guignard, M. Hauschild, M. Huijbregts, O. Jolliet, A. Kounina, V. Magaud, M. Margni, T.E. McKone, R.K. Rosenbaum, D. van de Meent, M. Schoorl, R. van Zelm, (2015) USEtox ${ }^{\circledR} 2.0$ Documentation (Version 1), USEtox ${ }^{\circledR}$ Team, Kgs. Lyngby, DOI:10.11581/DTU:00000011, http://orbit.dtu.dk/en/publications/usetox-20-documentation-version100(4459f65e-4f1c-4b87-984a-982b2b61ac39)/export.html.

[33] J.A. Meesters, A.A. Koelmans, J.T. Quik, A.J. Hendriks, D. van de Meent, Environ. Sci. Technol, 48 (2014) 5726-5736.

[34] H.H. Liu, Y. Cohen, Environ. Sci. Technol. 48 (2014) 3281-3292.

[35] A. Praetorius, M. Scheringer, K. Hungerbuhler, Environ. Sci. Technol. 46 (2012) 6705-6713 
[36] J.T. Quik, I. Velzeboer, M. Wouterse, A.A. Koelmans, D. van de Meent, Water Res. 48 (2014) 269-279.

[37] Y. Pu, F. Tang, P.M. Adam, B. Laratte, R.E. Ionescu, Environ. Sci. Technol. 50 (2016) 9370-9379.

[38] A. Praetorius, N. Tufenkji, K.-U. Goss, M. Scheringer, F. von der Kammer, M. Elimelech, Environ. Sci.: Nano 1 (2014) 317-323.

[39] G.M. Mutlu, G.R. Budinger, A.A. Green, D. Urich, S. Soberanes, S.E. Chiarella, G.F. Alheid, D.R. McCrimmon, I. Szleifer, M.C. Hersam, Nano Lett. 10 (2010) 1664-1670.

[40] C. Dahlgren, A. Karlsson, J. Immunol. Methods 232 (1999) 3-14.

[41] D. Prilutsky, B. Rogachev, R.S. Marks, L. Lobel, M. Last, Artif. Intell. Med. 52 (2011) 153-163.

[42] V. Brinkmann, U. Reichard, C. Goosmann, B. Fauler, Y. Uhlemann, D.S. Weiss, Y. Weinrauch, A. Zychlinsky, Science 303 (2004) 1532-1535.

[43] E. Kolaczkowska, P. Kubes, Nat. Rev. Immunol. 13 (2013) 159-175.

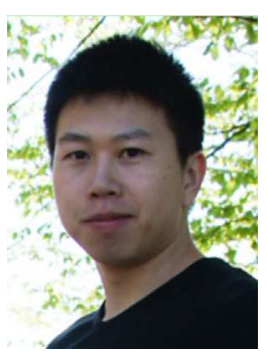

Yubing Pu is currently pursuing his Ph.D. studies at University of Technology of Troyes under the supervision of Prof. Ionescu and Dr. Laratte. He received his bachelor degree in environmental science in 2010 at Shandong Jianzhu University and master degree in chemistry in 2013 at China University of Geosciences (Beijing). In 2011 and 2012, he engaged in scientific research as a visiting student in Research Center for Eco-Environmental Sciences, Chinese Academy of Sciences. He is interested in the nanosafety areas related to the impacts of manufactured nanomaterials on human and ecosystem.

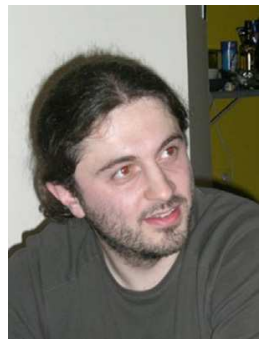

Bertrand Laratte is an associate professor at the Institute of Mechanics and Engineering, Arts et Métiers ParisTech. Between 2014 and 2016, he was an associate professor at the Research Centre for Environmental Studies and Sustainability, University of Technology of Troyes (UTT). He received his Ph.D. degree in 2013 at UTT. He spent more than 5 years as an expert in life cycle assessment in a consulting company before joining UTT for his Ph.D. His research interests mainly merge experimentation and collection data with environmental modeling to assess the potential environmental impacts. His contribution has the ambition to help mechanical design and industrial processes in order to reduce the environment risks.

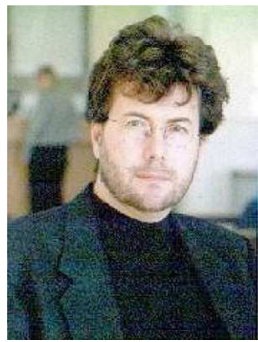

Robert S. Marks is a full professor at the Department of Biotechnology Engineering, the Ben-Gurion University of the Negev, Israel, and affiliated to the National Institute for Biotechnology in the Negev and the Ilse Kats Centre for Nanotechnology. His Ph.D. was done at the Weizmann Institute of Science (vaccines) in 1992, postdoc at the University of Cambridge (biosensors) in 1992-1994. Dr. Marks was the co-coordinator for the NRF CREATE program "Nanomaterials for Water and Energy Management" through MSE at the Nanyang Technological University from 2011 to 2016 . His research interests lie in the development of new viral biosensor configurations (Ebola virus, West Nile virus, Rift Valley fever, Dengue, Hepatitis C), environmental toxicology and nanometer particle-sensitive bioassays.

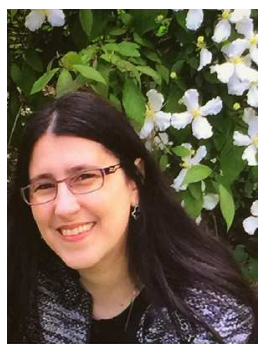

Rodica E. Ionescu is an associate professor of (nano)(bio)chemistry at the Laboratory of Nanotechnology, Instrumentation and Optics, Institute Charles Delaunay, University of Technology of Troyes since December 4th, 2009. She earned one Ph.D. in 2004 at the Ben-Gurion University of Negev, in Biotechnological Engineering and a second $\mathrm{PhD}$ in 2007 at the University of Bucharest, in Chemistry From April 1st 2014 to March 30, 2015 Dr. Ionescu was the scientific manager of a POC-NRF Grant "Electrochemical lateral flow biosensor for detection and quantification of dengue virus in whole blood" at the Nanyang Technological University, Singapore. Her current research activities include the development of multi-analytes biosensing and toxicity platforms for medical and environmental applications. 